\title{
Article \\ Evolution of Shear Band in Plane Strain Compression of Naturally Structured Clay with a High Sensitivity
}

\author{
Bingheng Liu ${ }^{1,2} \oplus$, Lingwei Kong ${ }^{1,2, *} \mathbb{C}$, Chengsheng $\mathrm{Li}^{3}$ and Juntao Wang ${ }^{1,2}$ \\ 1 State Key Laboratory of Geomechanics and Geotechnical Engineering, Institute of Rock and Soil Mechanics, \\ Chinese Academy of Sciences, Wuhan 430071, China; liubingheng17@mails.ucas.ac.cn (B.L.); \\ wangjuntao17@mails.ucas.edu.cn (J.W.) \\ 2 School of Engineering Science, University of Chinese Academy of Sciences, Beijing 100049, China \\ 3 Department of Civil and Environmental Engineering, Shantou University, Shantou 515063, China; \\ chengshengli@stu.edu.cn \\ * Correspondence: lwkong@whrsm.ac.cn
}

Citation: Liu, B.; Kong, L.; Li, C.; Wang, J. Evolution of Shear Band in Plane Strain Compression of Naturally Structured Clay with a High Sensitivity. Appl. Sci. 2022, 12, 1180. https://doi.org/10.3390/ app12031180

Academic Editor: Muhammad Junaid Munir

Received: 30 December 2021

Accepted: 22 January 2022

Published: 23 January 2022

Publisher's Note: MDPI stays neutral with regard to jurisdictional claims in published maps and institutional affiliations.

Copyright: (C) 2022 by the authors. Licensee MDPI, Basel, Switzerland. This article is an open access article distributed under the terms and conditions of the Creative Commons Attribution (CC BY) license (https:// creativecommons.org/licenses/by/ $4.0 /)$.

\begin{abstract}
The formation of the shear band is associated with the failure of soil. However, there has been relatively little investigation on the evolution of shear bands in naturally structured clay with a high sensitivity. In this study, undrained plane strain compression tests, digital image correlation (DIC) analyses, and scanning electron microscopy (SEM) tests were performed to investigate the characteristics of shear bands in naturally structured clay. The basic mechanical properties and stress-strain relationships show that naturally structured clay exhibits a strong structure and high sensitivity. Compared with plane strain compression tests under low confining pressure, more localized shear bands emerge in the specimens during the tests under high confining pressures; however, when the specimens fail, only one shear band is fully developed, and the local deformation in the developed shear band is much larger than those in other localized shear bands. Moreover, the local stress-strain relationships inside and outside the shear band show distinct discrepancies. The SEM results show distinct micro-structures of clays inside and outside the shear band, which are caused by the development of the shear band. The findings in this work provide new insight into the failure of structured clay.
\end{abstract}

Keywords: plane strain compression test; strain localization; shear band; digital image correlation; scanning electron microscopy test

\section{Introduction}

Shear band is defined as a band-shaped zone where the strain inside the zone is significantly greater than that outside the zone when the soil is subjected to external forces. The formation of a shear band significantly affects the failure of soil [1-4]; when the external load of the soil is higher than the strength of the soil, shear failure will occur along the shear band. Naturally structured clays are founded in many countries around the world, such as Ariake clay in Japan [5] and Batiscan clay in Canada [6], and they are also widely distributed in coastal areas of China. Naturally structured clay possesses complicated mechanical properties owing to soil structure. Researchers conducted extensive research on its mechanical behavior, including its compressibility and shear strength [7-9]. The mechanical properties of specimens under consolidation stress lower and higher than yield stress differ significantly. For example, in oedometer tests, when the effective vertical stress is lower than the yield stress, undisturbed specimens show low compressibility; when the effective vertical stress is higher than the yield stress, undisturbed specimens show high compressibility.

With the rapid economic development in China's coastal areas, many infrastructures, such as buildings and highways, are built on naturally structured clay layers. In the construction of these infrastructures, excavation works are inevitable, such as foundation 
pits and ditches. Therefore, artificial slopes are often produced, so it is necessary to ensure the safety of slopes to avoid safety accidents. Unfortunately, in recent years, a large number of landslides have occurred on naturally structured clay layers in China's coastal areas, such as Shanghai, Nanjing, Hangzhou, and other major cities [10], which have caused great difficulties for infrastructure construction. Because the formation and development of shear bands are associated with failure of soil slopes [11-13], the evolution of shear band is crucial for investigating the mechanics of naturally structured clay and ensuring the safety of infrastructures [14-16].

The study of shear bands can be traced back to the research on strain localization theory by Thomas [17]. Owing to the development of testing technology in recent years, many effective testing methods have been applied to investigate shear bands. Li et al. [18] studied the shear band inclination in Shanghai clay using local displacement sensors. Yuan et al. [19] took advantage of local pore water pressure sensors to investigate the shear bands formation of Shanghai silty clay in plane strain compression. Feng et al. [20] investigated the characteristics of shear bands of coral sand in the interface shear tests based on the digital image correlation (DIC) technique. Gylland et al. [21] analyzed the inner structure of shear bands in sensitive clays using the computed tomography (CT) measurements. Among the testing methods mentioned above, the most effective testing methods for investigating shear bands are the DIC technique and CT measurements [22,23]. Compared with DIC, which can only measure the surface deformation of specimens, CT can measure the inner deformation of specimens non-destructively, rendering its superior over DIC. Only limited heterogeneous geotechnical materials are suitable for CT measurements, such as granular materials with high quartz contents, as high speckle quality for local deformation calculation can be obtained owing to the density difference between quartz and air $[24,25]$. However, for natural clay, almost no density difference occurs inside it owing to its homogeneity. Hence, its internal speckle quality is insufficient for local deformation calculations in CT measurements. The DIC technique is a better method for natural clay because it can yield information pertaining to the formation and development of shear bands by measuring the deformation distribution of the surface of the specimens. To investigate shear bands, geotechnical testing methods, including conventional triaxial compression and plane strain compression tests, can be used. Because of the different stress states of the specimens in the two tests above, the characteristics of the shear band are different. For example, for quick clay, the shear band emerges before or at the peak deviatoric stress in the triaxial compression test, whereas the shear band emerges after the peak deviatoric stress in the plane strain compression test $[15,26]$. For sand, the shear band emerges before the peak deviatoric stress in the plane strain compression test, and the shear band emerges after the peak deviatoric stress in the triaxial compression test [27]. Therefore, the characteristics of the shear bands are also related to the types of soils. Because the clays in slopes are under stress conditions very close to plane strain $[26,28,29]$, plane strain compression tests were performed in this study.

A study pertaining to the evolution of shear bands in the plane strain compression of a naturally structured clay with a high sensitivity in coastal areas of Zhanjiang City, Guangdong Province, China (Zhanjiang clay), is reported herein. The strain field in the specimen was obtained during the plane strain compression test, and the micro-structures of the clay samples inside and outside the shear band were analyzed via scanning electron microscopy (SEM).

\section{Materials and Methods}

\subsection{DIC Technique}

The basic principle of the DIC technique is to match geometric points on digital speckle images under different conditions on the surface of an object and track the movements of the points to obtain information regarding surface deformation. DIC analysis software was used to process the photographs of the specimen at different stages in the test to calculate the displacement and strain distributions. In this study, the equivalent strain 
distribution was used to characterize the shear strain distribution in the specimens with the development of strain in the $z$-direction. The equivalent strain $\varepsilon_{e q}$ is defined as follows:

$$
\varepsilon_{e q}=\sqrt{\frac{2}{9}\left[\left(\varepsilon_{x}-\varepsilon_{y}\right)^{2}+\left(\varepsilon_{y}-\varepsilon_{z}\right)^{2}+\left(\varepsilon_{z}-\varepsilon_{x}\right)^{2}+6\left(\varepsilon_{x y}{ }^{2}+\varepsilon_{y z}{ }^{2}+\varepsilon_{z x}{ }^{2}\right)\right]},
$$

where $\varepsilon_{x}, \varepsilon_{y}$, and $\varepsilon_{z}$ are the strains in the $x-, y^{-}$, and $z$-directions, respectively; $\varepsilon_{x y}, \varepsilon_{y z}$, and $\varepsilon_{z x}$ are the shear strains in the planes perpendicular to $x-, y-$, and $z$-directions, respectively. All strains related to the $y$-direction are zero in the plane strain compression tests, and Equation (1) can be simplified to:

$$
\varepsilon_{e q}=\sqrt{\frac{2}{9}\left[\varepsilon_{x}^{2}+\varepsilon_{z}^{2}+\left(\varepsilon_{z}-\varepsilon_{x}\right)^{2}+6 \varepsilon_{z x}{ }^{2}\right]} .
$$

\subsection{Material}

As presented in Figure 1a, Zhanjiang City is located in the southeast coastal area of Guangdong Province, China. The city's economy is in a stage of rapid development, and infrastructure construction is also proceeding rapidly.

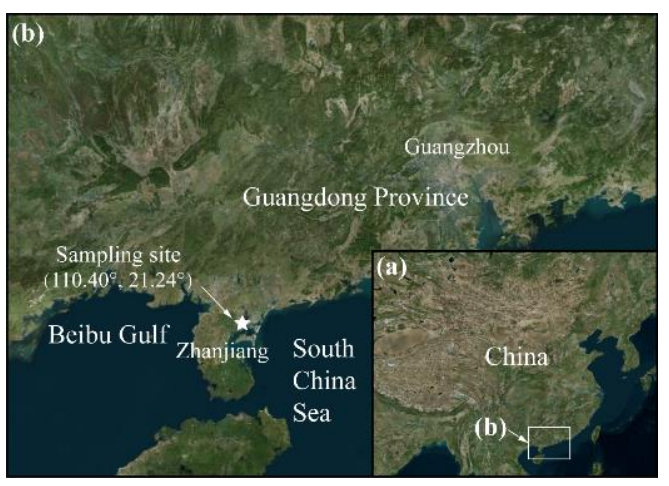

Figure 1. Sampling site of Zhanjiang clay: (a) location of Zhanjiang; (b) location of sampling site.

The clay samples were obtained from a coastal site in Zhanjiang City, with a sampling depth of 10-12 m. The specific location of sampling site is shown in Figure 1b. Zhanjiang clay is an interactive marine and terrestrial deposit. The detailed physical properties and grain size distribution of Zhanjiang clay are shown in Table 1. Zhanjiang clay exhibits a high water content and void ratio. Table 2 summarizes the basic mechanical properties of Zhanjiang clay.

Table 1. Physical properties and grain size distribution of Zhanjiang clay.

\begin{tabular}{ccccccccc}
\hline $\begin{array}{l}\text { Sampling } \\
\text { Depth (m) }\end{array}$ & $\begin{array}{c}\text { Natural } \\
\text { Density } \\
\left(\mathbf{g} / \mathrm{cm}^{3}\right)\end{array}$ & Void Ratio & $\begin{array}{c}\text { Moisture } \\
\text { Content } \\
\mathbf{( \% )}\end{array}$ & $\begin{array}{c}\text { Liquid } \\
\text { Limit (\%) }\end{array}$ & $\begin{array}{c}\text { Plastic } \\
\text { Limit (\%) }\end{array}$ & $\begin{array}{c}\text { Hydraulic } \\
\text { Conductiv- } \\
\text { ity } \\
(\mathbf{c m} / \mathbf{s})\end{array}$ & $\begin{array}{c}\text { Grain Size Distribution } \\
\text { (\%) }\end{array}$ & $\begin{array}{c}\mathbf{0 . 0 0 5 -} \\
\mathbf{0 . 0 7 5} \mathbf{~ m m}\end{array}$ \\
\hline $10-12$ & 1.75 & 1.45 & 54.92 & 62.2 & 28.8 & $2.7 \times 10^{-8}$ & 59.1 & 40.9 \\
\hline
\end{tabular}

Table 2. Mechanical properties of Zhanjiang clay.

\begin{tabular}{ccccc}
\hline $\begin{array}{c}\text { Overburden Pressure } \\
(\mathbf{k P a})\end{array}$ & Yield Stress (kPa) & $\begin{array}{c}\text { Unconfined } \\
\text { Compressive Strength } \\
\text { of Undisturbed Clay } \\
\mathbf{( k P a )}\end{array}$ & $\begin{array}{c}\text { Unconfined } \\
\text { Compressive Strength } \\
\text { of Remolded Clay } \\
(\mathbf{k P a})\end{array}$ & Sensitivity \\
\hline 200 & 350 & 110.6 & 17.2 & 6.4 \\
\hline
\end{tabular}


As mentioned in the previous section, yield stress $\sigma_{\text {yield }}$ is an important mechanical index for structured clay. Hong et al. [30] suggested that the yield stress $\sigma_{\text {yield }}$ should be determined from the one dimensional compression curve of undisturbed specimen in the $\log (e+1)-\log \left(\sigma_{v}^{\prime}\right)$ plot, where $e$ is the void ratio of specimen, and $\sigma_{v}^{\prime}$ is the effective vertical stress applied in the tests. As illustrated in Figure 2, the average value of $\sigma_{\text {yield }}$ for the undisturbed clay samples deduced from the two compression tests is approximately $350 \mathrm{kPa}$, whereas the overburden pressure of the clay samples is approximately $200 \mathrm{kPa}$, implying that the yield stress and the overburden pressure differ significantly.

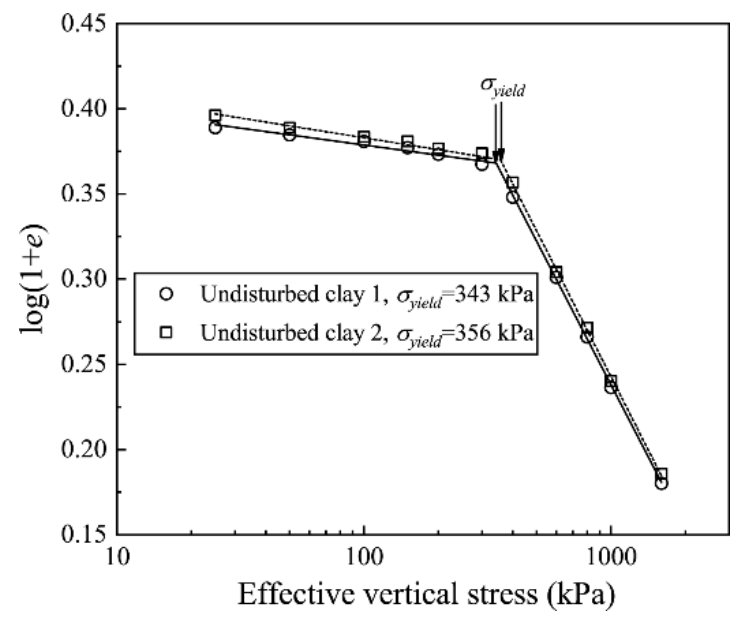

Figure 2. Typical compression curves of undisturbed Zhanjiang clay in the $\log (1+e)-\log \left(\sigma_{v}^{\prime}\right)$ plot.

Figure 3 shows that the average value of unconfined compressive strength of undisturbed clay is $110.6 \mathrm{kPa}$, whereas that of remolded clay is only $17.2 \mathrm{kPa}$. Therefore, the sensitivity value of Zhanjiang clay is approximately 6.4. Based on the classification of Rosenqvist [31], clays with a sensitivity value greater than 4 are classed as very sensitive. Therefore, Zhanjiang clay is classed as very sensitive clay. The undisturbed clay has a high unconfined compressive strength, even though its physical properties are relatively poor for engineering application (Table 1). The high yield stress and high sensitivity of Zhanjiang clay are primarily due to its strong structure that stems primarily from the natural cementation of free iron oxides [32,33].

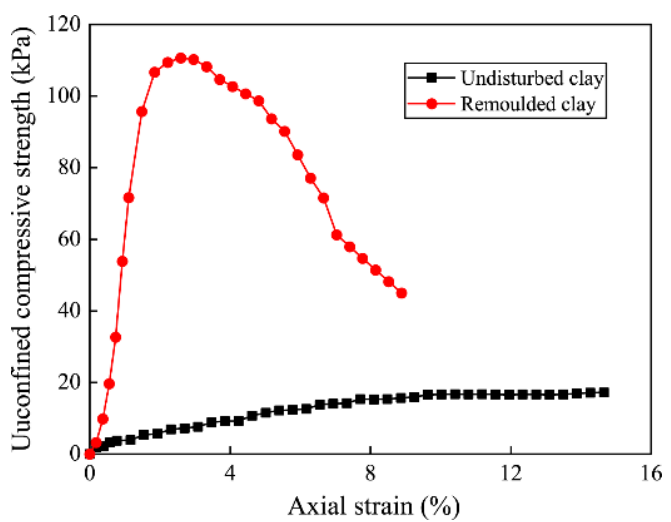

Figure 3. Curves for unconfined compression tests of undisturbed clay and remolded clay.

\subsection{Test Apparatus}

Figure 4a shows the plane strain testing apparatus used in this study. Figure $4 \mathrm{~b}$ presents a detailed schematic illustration of the pressure chamber and the stress state of the specimen. As shown in Figure $4 \mathrm{~b}$, the plane strain testing apparatus is modified from the true triaxial apparatus with mixed rigid and flexible boundaries. The load in the 
$z$-direction (vertical load) is supplied by the top and bottom rigid plates. The load in the $x$-direction is provided by the cell pressure in the chamber. Two glass plates are installed in the $y$-direction to maintain the zero strain in the $y$-direction, thereby maintaining the specimen under the plane strain condition. In the $y$-direction of the pressure chamber wall, two symmetrical glass windows are used to observe the specimen during the tests.

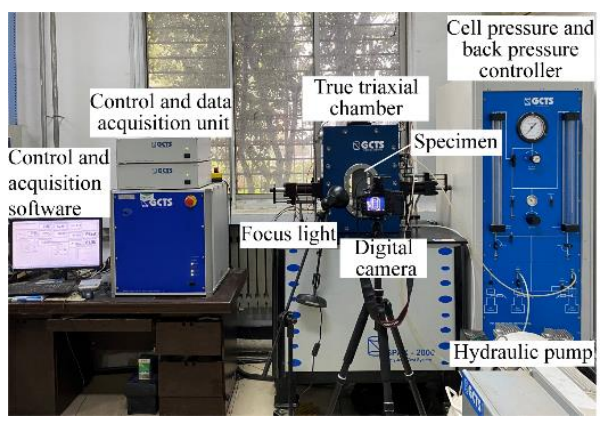

(a)

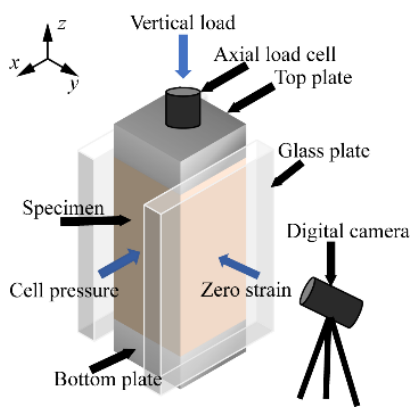

(b)

Figure 4. Testing apparatus: (a) photograph of the plane strain testing apparatus; (b) schematic of compositions of the pressure chamber and the stress state of the specimen.

\subsection{Sample Preparation and Test Procedure}

In this study, undisturbed clays were cut into cuboid specimens. Figure 5a shows a schematic illustration of the specimen. The dimensions of the cubic specimen are $160 \mathrm{~mm}$ $\times 75 \mathrm{~mm} \times 75 \mathrm{~mm}$.

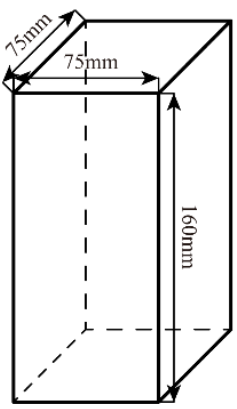

(a)

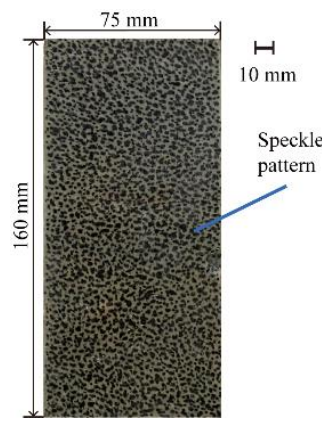

(b)

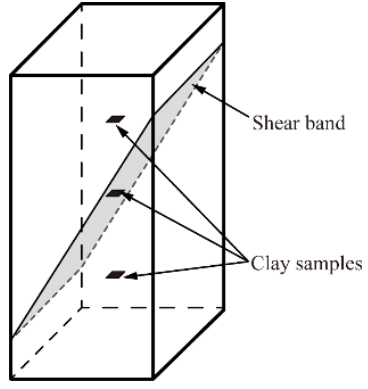

(c)

Figure 5. Specimen preparation: (a) schematic of the specimen; (b) photograph of speckle pattern on membrane; (c) schematic of sampling points used for SEM tests.

First, the specimen was placed inside the membrane, and speckles with a diameter of 2-10 mm necessary for DIC analyses were painted on the membrane, as shown in Figure 5b. Prior to the test, the specimen was mounted in the test apparatus, and silicone grease was applied to the membrane to eliminate the friction between the rubber membrane and rigid glass plates in the $y$-direction. Subsequently, the specimen was saturated at a back pressure of $200 \mathrm{kPa}$ with an effective stress of $20 \mathrm{kPa}$, which required more than $24 \mathrm{~h}$. When the $B$-values reached 0.98 , the specimens were consolidated to various values of confining pressure $\left(\sigma_{x}\right)$. To study the characteristics of shear bands of Zhanjiang clay at different depths (i.e., different pressures), the specimens were consolidated at 100, 200, 300, 400, and $500 \mathrm{kPa}$. When the drainage rate of pore water was less than $1 \mathrm{~mm}^{3} / \mathrm{min}$, the undrained plane strain compression tests were performed at an axial deformation ( $z$-direction) rate of $0.075 \mathrm{~mm} / \mathrm{min}$. Table 3 presents the test program in detail. 
Table 3. Test program.

\begin{tabular}{cccc}
\hline Number of Tests & $\begin{array}{c}\text { Confining Pressure } \\
(\mathbf{k P a})\end{array}$ & $\begin{array}{c}\text { Shearing Rate } \\
(\mathbf{m m} / \mathbf{m i n})\end{array}$ & Testing Conditions \\
\hline T1 & 100 & & \\
T2 & 200 & & \\
T3 & 300 & 0.075 & \\
T4 & 400 & & \\
T5 & 500 & & \\
\hline
\end{tabular}

During the plane strain compression tests, a series of photographs was captured using a digital camera (see Figure 4a) for DIC analysis. After performing the plane strain compression tests, the specimen was freeze-dried. The three small clay samples were carefully cut with a knife according to the sampling positions shown in Figure 5c. The dimension of the three clay samples is $1.5 \mathrm{~cm} \times 1.5 \mathrm{~cm} \times 1.5 \mathrm{~cm}$. Then, SEM tests were conducted on the three small clay samples obtained from the inside and outside of the shear band in the specimen.

\section{Results}

\subsection{Stress-Strain and Pore Water Pressure Behavior}

Figure 6a presents the curves of global deviatoric stress $\left(\sigma_{z}-\sigma_{x}\right)$ versus axial strain $\left(\varepsilon_{z}\right)$ from plane strain compression tests. As shown in Figure 6a, for specimens consolidated to confining pressures lower than $\sigma_{\text {yield }}=350 \mathrm{kPa}$, the $\left(\sigma_{z}-\sigma_{x}\right)-\varepsilon_{z}$ curves show post-peak reductions in deviatoric stress and strain-softening behaviors. As the axial strain increases, the deviatoric stress first increases to a peak and then decreases, and the peak deviatoric stress appears at a small axial strain $\left(\varepsilon_{z}=2-3 \%\right)$, exhibiting the typical stress-strain behavior of naturally structured clay. Significant differences in stress-strain behavior are observed between the other natural clays and Zhanjiang clay; the stress-strain curves of the former either do not indicate a remarkable peak deviatoric stress, or the peak deviatoric stress appears at $\varepsilon_{z} \geq 5 \%[18,19,26]$. For specimens consolidated to confining pressures higher than $\sigma_{\text {yield }}$ (i.e., $\sigma_{x}=400$ and $500 \mathrm{kPa}$ ), no significant strain-softening behavior is observed. The deviatoric stress first increases to a peak (at approximately $\varepsilon_{z}=6 \%$ ) and then decreases slightly $\left(\sigma_{x}=400 \mathrm{kPa}\right)$ or remains flat $\left(\sigma_{x}=500 \mathrm{kPa}\right)$ as $\varepsilon_{z}$ increases. Similar results were obtained in conventional triaxial tests performed on naturally structured clays $[7,33]$.

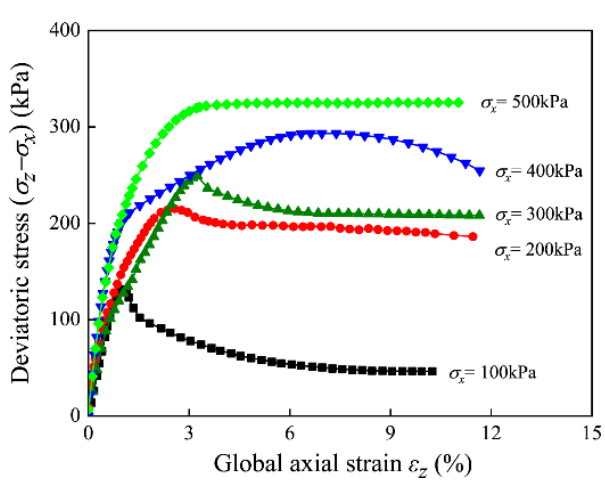

(a)

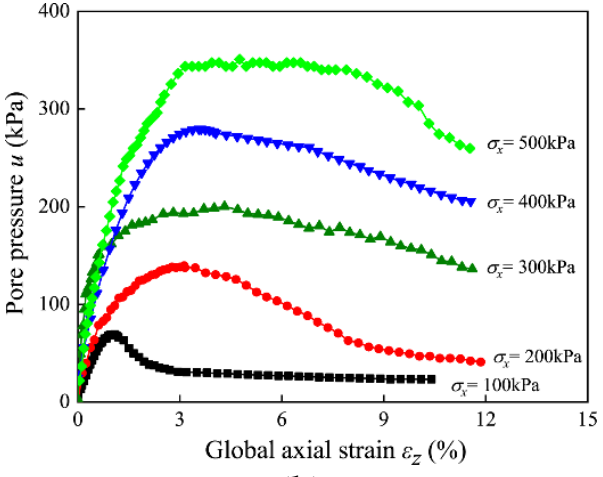

(b)

Figure 6. Global stress-strain and pore water pressure behavior for plane strain compression tests: (a) deviatoric stress $\left(\sigma_{z}-\sigma_{x}\right)$-axial strain $\left(\varepsilon_{z}\right)$ curves; $(\mathbf{b})$ pore water pressure $(u)$-axial strain $\left(\varepsilon_{z}\right)$ curves.

Figure $6 \mathrm{~b}$ presents the curves of global pore water pressure $(u)$ versus axial strain $\left(\varepsilon_{z}\right)$. First, the pore water pressure increases with increasing $\varepsilon_{z}$, and, once the pore water pressure reaches its peak, it decreases as $\varepsilon_{z}$ increases. The value of $\varepsilon_{z}$ at the peak pore water pressure is slightly higher than that at the peak deviatoric stress, which is a typical phenomenon of naturally structured clay. 


\subsection{Characteristics of Shear Band}

\subsubsection{Evolution of Shear Bands}

To investigate the evolution of the shear band of specimens, a series of photographs was captured during plane strain compression tests for specimens consolidated to 100, 300, and $500 \mathrm{kPa}$. When the localized shear band develops into an evident shear band, and the stress-strain relationship is at a steady stage after the peak deviatoric stress, the shear band is considered as fully developed. DIC analyses were carried out for the T1, T3, and T5 tests at seven typical moments before the peak, at the peak, after the peak, and at the steady stage of the deviatoric stress, respectively. The local strain distributions were computed by comparing an image with its initial image, and the images of the strain fields at the seven moments were distinguished by the value of the global axial strain $\varepsilon_{z}$. The results of the local equivalent strain $\left(\varepsilon_{e q}\right)$ distribution and stress-strain relationship for the T1, T3, and T5 tests are shown in Figures 7-9.

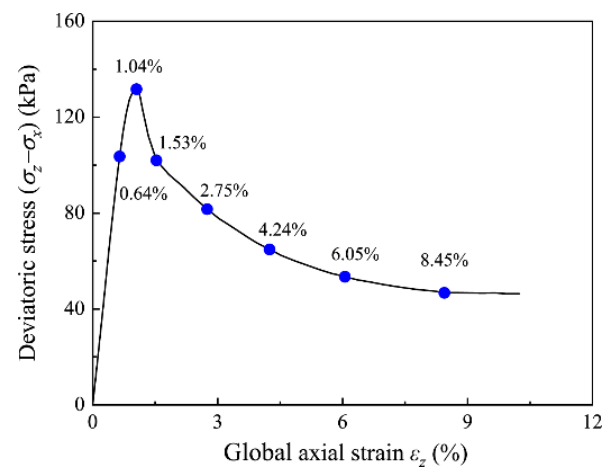

(a)

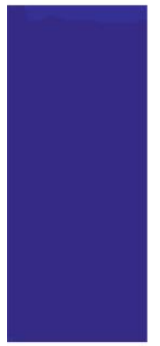

$\varepsilon_{z}=0.64 \%$

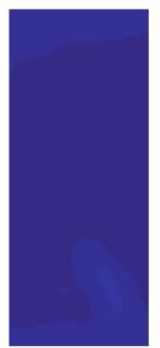

$\varepsilon_{z}=1.04 \%$

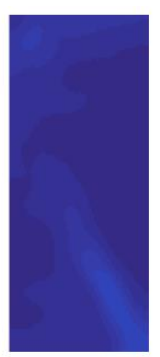

$\varepsilon_{z}=1.53 \%$

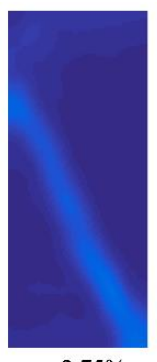

$\varepsilon_{z}=2.75 \%$

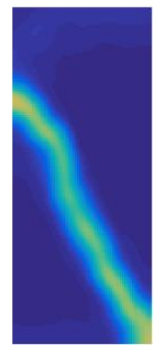

$\varepsilon_{z}=4.24 \%$

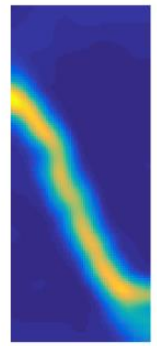

$\varepsilon_{z}=6.05 \%$

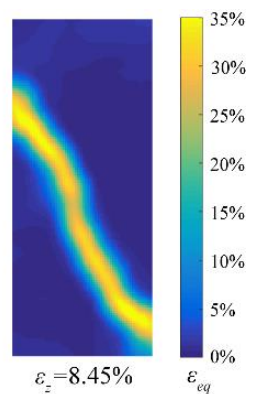

(b)

Figure 7. Results of DIC analyses for the T1 test: (a) global stress-strain relationship for the T1 test; (b) shear strain distribution at different stages in the T1 test.

For the T1 test, the global stress-strain curve and the distribution of $\varepsilon_{e q}$ calculated using the DIC technique are shown in Figure 7a,b, respectively. The image of $\varepsilon_{e q}=0.64 \%$ indicates no significant strain localization, as the local strain is relatively uniform in the specimen. However, in plane strain compression tests of the other natural clays $[19,26]$, evident strain localization appears at $\varepsilon_{z}=3-5 \%$. In other words, compared with the other natural clay, conspicuous strain localization appears at a small axial strain in Zhanjiang clay. The peak deviatoric stress is reached when $\varepsilon_{z}=1.04 \%$; however, the fully developed shear band does not appear in the specimen. The maximum $\varepsilon_{e q}$ at this time is $2.67 \%$, and strain localization appears only at the lower right corner of the specimen. When $\varepsilon$ increases from $1.53 \%$ to $2.75 \%$, accompanied by severe strain-softening, a band zone with localized shear strain (localized shear band) extends to the upper left of the specimen and gradually develops into a curved shear band. When $\varepsilon_{z}$ increases from $2.75 \%$ to $8.45 \%$, the stress-strain relationship is in a steady stage after the peak deviatoric stress, and the thickness of the shear band increases with increasing $\varepsilon_{z}$. The maximum $\varepsilon_{e q}$ inside the shear band exceeds 
$35 \%$ at $\varepsilon_{z}=8.45 \%$. When the specimen failed, the specimen was divided into two parts by the shear band.

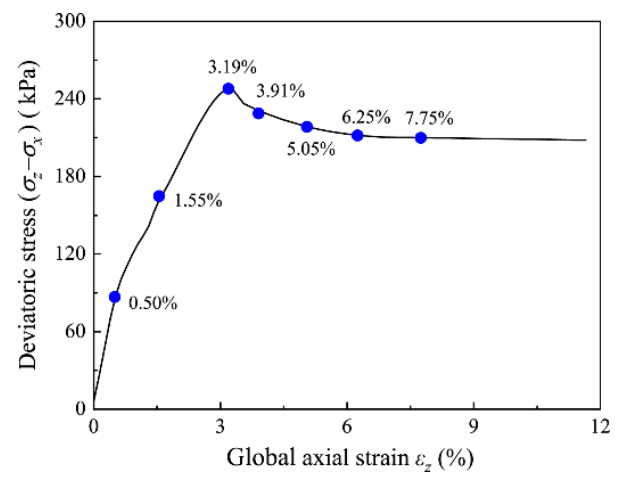

(a)

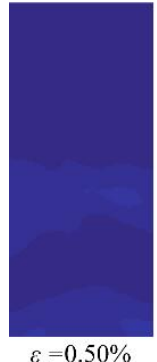

$\varepsilon_{z}=0.50 \%$

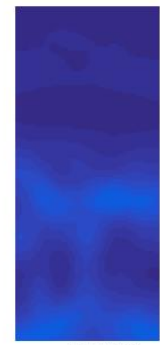

$\varepsilon_{z}=1.55 \%$

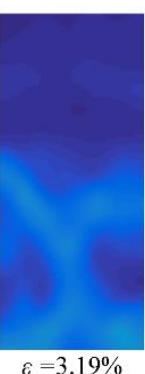

$\epsilon_{-}=3.19 \%$
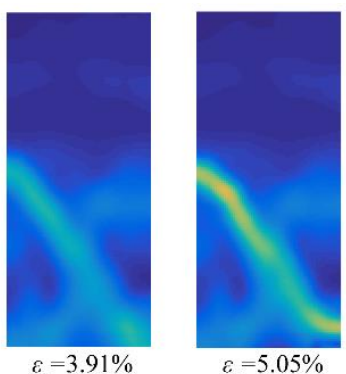

$\varepsilon_{2}=5.05 \%$

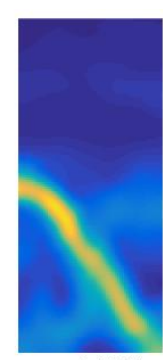

$\varepsilon_{z}=6.25 \%$

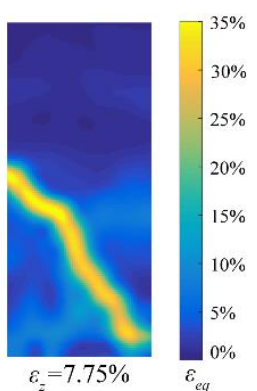

(b)

Figure 8. Results of DIC analyses for the T3 test: (a) global stress-strain relationship for the T3 test; (b) shear strain distribution at different stages in the T3 test.

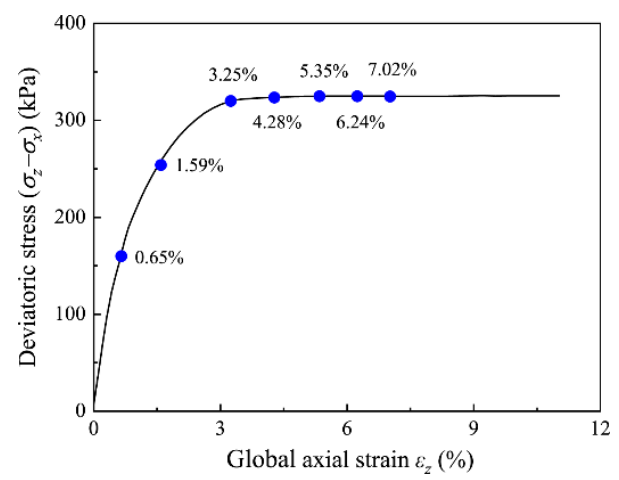

(a)

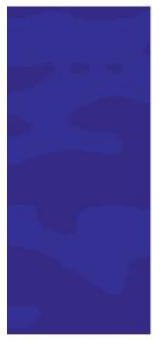

$\varepsilon_{z}=0.65 \%$

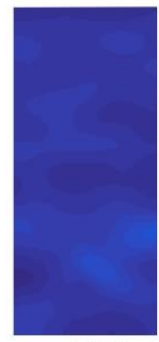

$\varepsilon_{z}=1.59 \%$

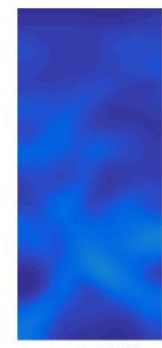

$\varepsilon=3.25 \%$

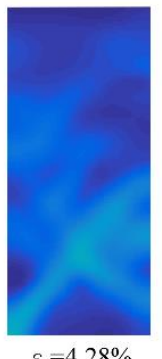

$\varepsilon_{z}=4.28 \%$

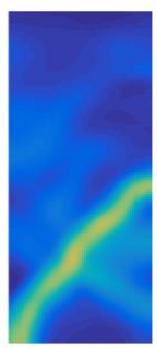

$\varepsilon_{z}=5.35 \%$

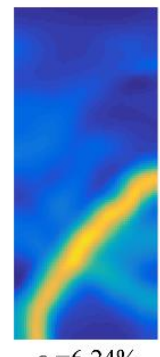

$\varepsilon_{-}=6.24 \%$

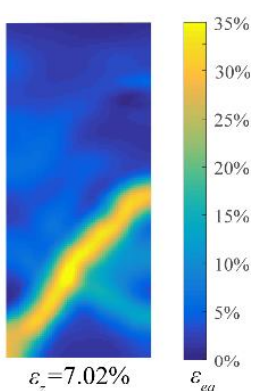

$\varepsilon_{z}=7.02 \% \quad \varepsilon_{e y}$

(b)

Figure 9. Results of DIC analyses for the T5 test: (a) global stress-strain relationship for the T5 test; (b) shear strain distribution at different stages in the T5 test. 
For the T3 test, as shown in Figure 8b, unlike the T1 test, two conjugated localized shear bands appear when $\varepsilon_{z}=1.55 \%$. As the axial strain increases, the thickness of both localized shear bands increases accordingly. However, $\varepsilon_{e q}$ in the localized shear band that inclined to the left increases faster than $\varepsilon_{e q}$ in the localized shear band that inclined to the right after the peak deviatoric stress. When $\varepsilon_{z}=5.05 \%$, the maximum values of $\varepsilon_{e q}$ in the localized shear band that inclined to the left and right are $26.36 \%$ and $14.52 \%$, respectively. When $\varepsilon_{z}=7.75 \%$, the maximum value of $\varepsilon_{e q}$ in the localized shear band that inclined to the left exceeds $35.0 \%$, and the shear band that inclined to the left develops into a shear band. Under confining pressure of $300 \mathrm{kPa}$, two conjugated localized shear bands appear in the specimen, but only one fully developed shear band is formed where the local shear strain increases significantly.

For the T5 test, similar to the other natural clays [19,26], obvious strain localization emerges at $\varepsilon_{z} \geq 2.0 \%$, unlike the specimens in the T1 and T3 tests. As shown in Figure 9b, the local shear strain distribution is much more complicated than those of the T1 and T3 tests. When $\varepsilon_{z}=3.25 \%$, the deviatoric stress reaches its peak, and several localized shear bands appear in the specimen. When $\varepsilon_{z}$ increases from $3.25 \%$ to $7.02 \%$, similar to the result of the T3 test, one of the localized shear bands that is more developed than the others become dominant. When $\varepsilon_{z}$ reaches $7.02 \%$, a fully developed shear band is formed in the lower section of the specimen.

\subsubsection{Local Stress-Strain Relationship}

The local strain in the specimens is not uniform (see Figures 7-9) in the plane strain compression tests, which may lead to the differences in the global and local stress-strain relationships. The global stress-strain relationships are obtained from the results of plane strain compression tests (see Figure 6a). Several typical regions in the specimens are selected to obtain the local stress-strain relationships. The local axial strain calculated via DIC analyses is the mean axial strain of all points in the selected region, and the value of the deviatoric stress is obtained from the average stress of the layer where the region is located. The global and local stress-strain relationships for the T1, T3, and T5 tests are shown in Figure 10.

For the T1 test, the local stress-strain relationships of two regions outside the shear band ( $\mathrm{A}$ and $\mathrm{C}$ ) and one region in the shear band (B) are analyzed (the specific locations are shown in Figure 10a). As shown in Figure 10b, the stress-strain curves of regions A, B, and $\mathrm{C}$ are similar to the global stress-strain curve before the peak deviatoric stress. However, the stress-strain curves for different regions after the peak deviatoric stress indicate distinct differences. The strain softening in the stress-strain curve for the regions inside the shear band is more gradual than that of the global stress-strain curve, whereas the deviatoric stress in the stress-strain curve for the regions inside the shear band reduces significantly. When the shear band is fully developed, the local axial strain in regions inside the shear band is significantly greater than that in regions outside the shear band. The global axial strain is approximately $7.6 \%$, and the values of local axial strain in regions $\mathrm{A}, \mathrm{B}$, and $\mathrm{C}$ is $0.84 \%, 17.3 \%$, and $0.72 \%$, respectively. For the T3 test, one region outside the shear band (A), one region inside the localized shear band (B), and one region inside the shear band (C) are analyzed (see Figure 10c). As shown in Figure 10d, the local axial strain in the region inside the localized shear band (B) that inclined to the right increases faster than that in the other regions; however, it stops increasing after the peak deviatoric stress. The local axial strain in the shear band inclined to the left increases slowly before the peak deviatoric stress but increases rapidly after the peak deviatoric stress. Finally, a fully developed shear band that inclined to the left is formed. The local stress-strain behavior verifies the experimental phenomenon shown in Figure 8. As shown in Figure 10e, the stress-strain curves of one region outside the shear band (A), two regions inside the localized shear bands (B and $\mathrm{C}$ ), and one region inside the developed shear band (D) are analyzed for the T5 test. As shown in Figure 10f, the local axial strain in region D increases faster than that in regions B and C after the peak deviatoric stress. When the shear band is fully developed, the values of local 
axial strain in regions A, B, C, and D is $2.8 \%, 6.1 \%, 10.0 \%$, and $22.4 \%$, respectively. Only one shear band is fully developed, even though several shear bands emerge during the test.

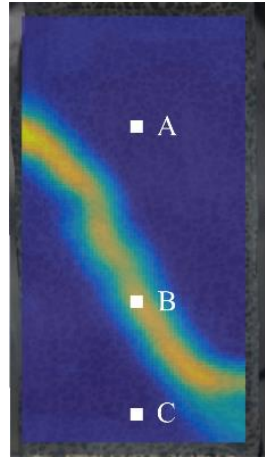

(a)

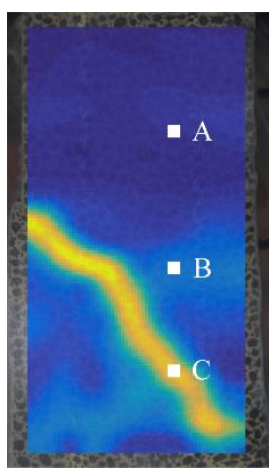

(c)

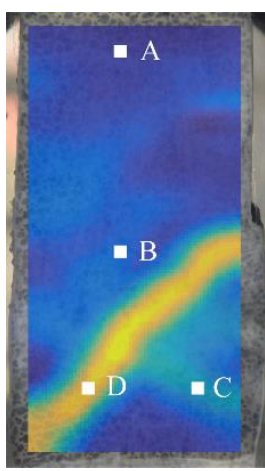

(e)

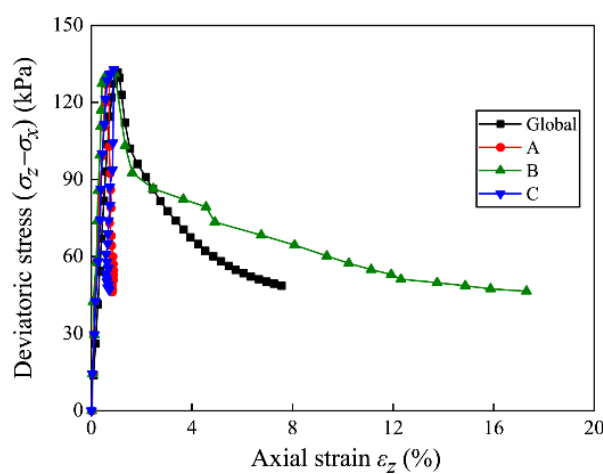

(b)

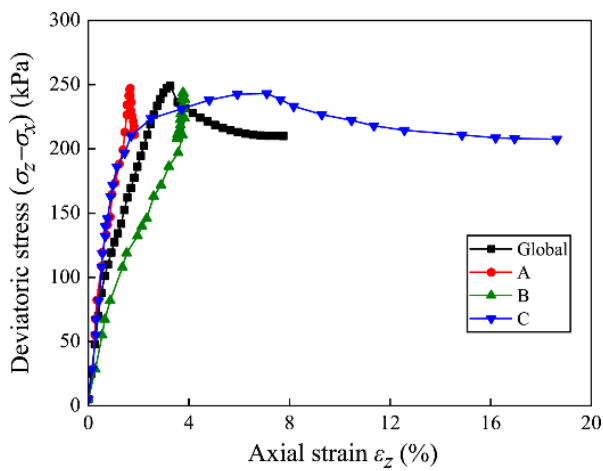

(d)

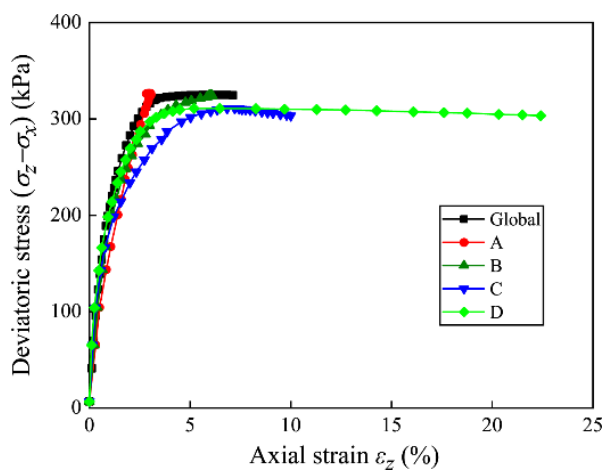

(f)

Figure 10. Global and local stress-strain relationships: (a,c,e) locations of typical regions in T1, T3, and T5 specimens; $(\mathbf{b}, \mathbf{d}, \mathbf{f})$ global stress-strain curves of T1, T3, and T5 specimens and local stress-strain curves of typical regions in $\mathrm{T} 1, \mathrm{~T} 3$, and $\mathrm{T} 5$ specimen.

\subsubsection{Inclinations of Shear Bands}

The inclination angle of the shear band is defined as the angle between the shear band and the direction of the minor principal stress. To analyze the inclination of the shear band, the following three theories were adopted.

Mohr-Coulomb theory:

$$
\theta_{M C}=45^{\circ}+\phi / 2
$$

Roscoe theory [34]:

$$
\theta_{R}=45^{\circ}+\psi / 2 \text {, and }
$$


Arthur solution [35]:

$$
\theta_{A}=45^{\circ}+(\phi+\psi) / 4,
$$

where $\phi$ is the internal friction angle obtained from the plane compression test, which is $23.8^{\circ}$, and $\psi$ is the dilation angle. Because the tests were undrained, the dilation angle of the specimen was zero. In fact, the dilation angle is not zero [18]. Since the local displacement can be calculated by the DIC technique, the dilation angle at failure can be obtained using the following equation $[4,18]$ :

$$
\psi=\theta_{M}-\arctan \frac{\Delta u_{z}}{\Delta u_{x}},
$$

where $\theta_{M}$ is the measured inclination of the shear band, and $\Delta u_{z}$ and $\Delta u_{x}$ are the incremental quantities of the local displacement in the $z$ and $x$-directions outside the shear band, respectively.

Table 4 summarizes the measured and calculated inclinations of the shear band. The measured inclination $\left(\theta_{M}\right)$ of shear bands in the T1, T3, and T5 tests are smaller than the inclinations calculated based on the three theories mentioned above. Because the shape of the shear band is very complicated, the prediction of the inclination of the shear band is not accurate. The measured inclinations are closer to the inclinations calculated based on Mohr-Coulomb theory, as reported by Hicher et al. [36] and Jiang et al. [37].

Table 4. Measured and calculated inclinations of shear bands.

\begin{tabular}{cccccc}
\hline $\begin{array}{c}\text { Number of } \\
\text { Tests }\end{array}$ & $\begin{array}{c}\text { Confining } \\
\text { Pressure } \\
\mathbf{( k P a )}\end{array}$ & $\boldsymbol{\theta}_{\boldsymbol{M}}\left({ }^{\circ}\right)$ & $\boldsymbol{\theta}_{M C}\left({ }^{\circ}\right)$ & $\boldsymbol{\theta}_{\boldsymbol{R}}\left(^{(}\right)$ & $\boldsymbol{\theta}_{A}\left({ }^{\circ}\right)$ \\
\hline T1 & 100 & 57.9 & 56.9 & 54.3 & 55.6 \\
T3 & 300 & 52.1 & 56.9 & 56.2 & 56.6 \\
T5 & 500 & 51.0 & 56.9 & 60.4 & 58.7 \\
\hline
\end{tabular}

\section{Discussion}

In contrast to the specimens at low confining pressures, no strain-softening is observed in the stress-strain curves for the specimens at high confining pressures, and the strain distributions are different. Only one or two localized shear bands emerge in the specimen consolidated to confining pressure lower than $\sigma_{\text {yield }}$. The number of localized shear bands increases with increasing confining pressures, and several localized shear bands appear in specimen consolidated to confining pressure greater than $\sigma_{\text {yield }}$. When the specimens fail, only one shear band is fully developed in all specimens. For the other natural clays $[18,19,26]$, one or several types of strain distributions were present in the specimen; however, they were not affected by the confining pressure. Zhang et al. [38] conducted mercury intrusion porosimetry (MIP) tests on Zhanjiang clay consolidated to different pressures, and the $\sigma_{\text {yield }}$ of the tested clay samples was $400 \mathrm{kPa}$. The specific MIP test results are presented in Figure 11 and Table 5. As shown in Table 5, the diameters of the pores $(d)$ of Zhanjiang clay can be classified into four categories: $d>10 \mu \mathrm{m}, 1 \mu \mathrm{m}<d<10 \mu \mathrm{m}$, $0.1 \mu \mathrm{m}<d<1 \mu \mathrm{m}$, and $d<0.1 \mu \mathrm{m}$. When the consolidation pressures are lower than or equal to $\sigma_{\text {yield }}$, the proportion of pores with different diameters does not change significantly (see Figure 11). However, when the consolidation pressure exceeds $\sigma_{\text {yield }}$, the proportion of pores with a diameter between 1 and $10 \mu \mathrm{m}$ decreases significantly, whereas the proportion of pores with a pore diameter between 0.1 and $1 \mu \mathrm{m}$ increases significantly (see Table 5). The phenomenon above shows that the pore size distribution of Zhanjiang clay changes substantially when the consolidation pressure exceeds $\sigma_{\text {yield }}$. The distribution of pore water pressure in the specimen during the plane strain compression is associated closely with the pore size distribution, whereas the pore water pressure has a significant influence on the formation of the shear band $[19,26]$. Therefore, the change in pore size distribution might have contributed to the different strain distributions in the specimens of Zhanjiang clay 
consolidated at different confining pressures. Further research is required to confirm the speculation above.

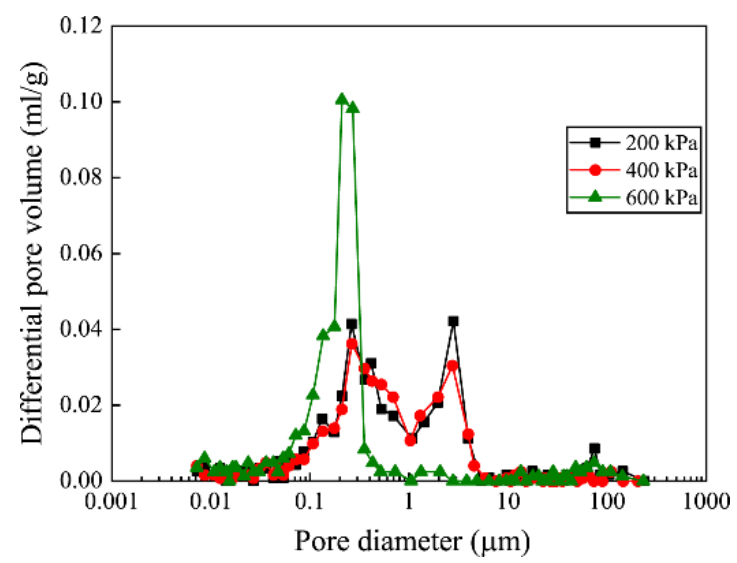

Figure 11. Pore size distribution density function curve of undisturbed Zhanjiang clay under various pressures [38].

Table 5. Pore size distribution in Zhanjiang clay under different consolidation pressures [38].

\begin{tabular}{|c|c|c|c|c|c|}
\hline \multirow{2}{*}{$\begin{array}{l}\text { Consolidation } \\
\text { Pressures } \\
(\mathbf{k P a})\end{array}$} & \multirow{2}{*}{$\begin{array}{c}\text { Percentage } \\
\text { of Pore } \\
\text { Volume }(\%)\end{array}$} & \multicolumn{4}{|c|}{ Percentage of Pore Volume with Different Diameters (\%) } \\
\hline & & $d>10 \mu \mathrm{m}$ & $\begin{array}{c}1 \mu \mathrm{m}<d< \\
10 \mu \mathrm{m}\end{array}$ & $\begin{array}{c}0.1 \mu \mathrm{m}<d< \\
1 \mu \mathrm{m}\end{array}$ & $d<0.1 \mu \mathrm{m}$ \\
\hline 200 & 59.41 & 9.1 & 26.7 & 50.9 & 13.3 \\
\hline 400 & 57.65 & 4.1 & 27.5 & 54.6 & 13.8 \\
\hline 600 & 53.10 & 7.3 & 1.1 & 72.1 & 19.5 \\
\hline
\end{tabular}

Figure 12 presents the SEM results of the clay sample outside and inside the shear band under the same magnification. By comparing the three SEM figures, it can be concluded that the pore size outside the shear band are larger than those in the shear band. With the development of the shear band, large pores in the shear band collapsed into small pores and particles in the shear band became more compact. This is consistent with the test results of marine clay [37]. In summary, the SEM results demonstrate that large differences in micro-structures are observed for clays inside and outside the shear band.

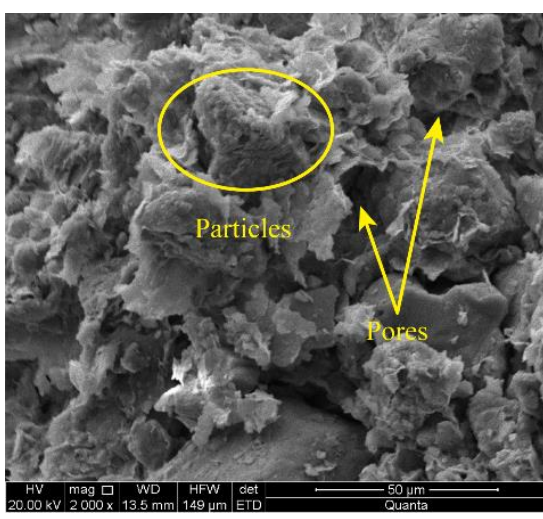

(a)

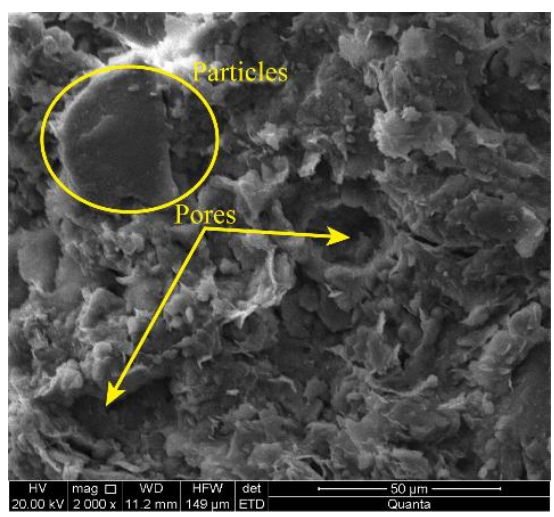

(b)

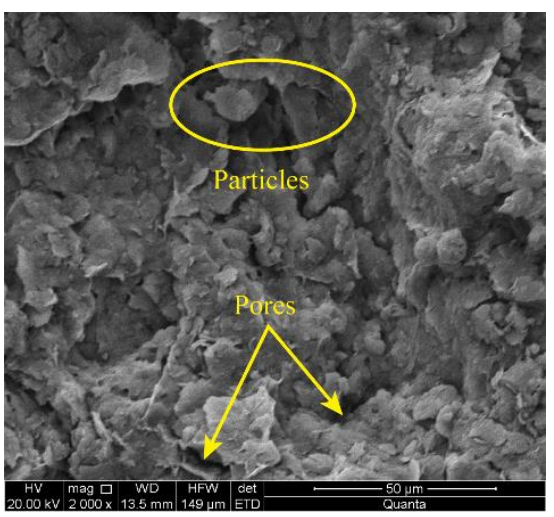

(c)

Figure 12. SEM results for clay: (a,b) outside the shear band; $(\mathbf{c})$ inside the shear band. 


\section{Conclusions}

This paper focuses on the evolution and characteristics of shear bands in Zhanjiang clay consolidated to various confining pressures. A series of undrained plane strain compression tests with DIC analyses and SEM tests was carried out. The conclusions are as follows:

(1) The basic mechanical properties and representative stress-strain behavior indicates that Zhanjiang clay is a typical naturally structured clay. The mechanical properties of specimens under consolidation stress lower and higher than yield stress differ significantly.

(2) When $\sigma_{x}=100 \mathrm{kPa}$, only one localized shear band appears in the specimen. However, when $\sigma_{x}=300$ and $500 \mathrm{kPa}$, several localized shear bands appear in the specimens during the plane strain compression tests, and the shear strain distribution is much more complicated when $\sigma_{x}=500 \mathrm{kPa}$. When the specimens fail, only one shear band is fully developed for all specimens, and the shear strain in the developed shear band is much larger than those in the other localized shear bands. Based on the results of MIP tests, the change in pore size distribution might have contributed to the different strain distributions in the specimens consolidated at different confining pressures. The measured inclination of the shear bands in the T1, T3, and T5 tests are similar to the inclinations calculated based on the Mohr-Coulomb theory.

(3) Before the peak deviatoric stress, the local strain in the specimens is relatively uniform, and the local stress-strain curves for regions inside and outside the shear band are similar. However, strain localization emerges subsequently, and the local stressstrain curves for regions inside and outside the shear band are distinct after the peak deviatoric stress.

(4) The SEM results indicate that the micro-structures inside and outside the shear band can be distinguished. The overall particle size and pore size outside the shear band are larger than those in the shear band, and the number of particles outside the shear band is lower than that in the shear band, owing to strain localization and development of the shear band.

In this study, the evolution and characteristics of shear bands in Zhanjiang clay, consolidated to various confining pressures, are investigated. The real-time evolutions of shear bands of Zhanjiang clay during the plane strain compression tests are obtained. In addition, the buried depths for clays were simulated by the various confining pressures, which contributes to study the shear band characteristics of clays at different positions of slopes under large forces. It is believed that this work would be helpful for the comprehensive understandings of failure of soil, and even the failure of slopes.

Author Contributions: Conceptualization, B.L. and L.K.; methodology, B.L.; software, formal analysis, C.L.; investigation, B.L. and J.W.; resources, L.K.; writing-original draft preparation, B.L.; writing-review and editing, B.L. and L.K.; supervision, L.K.; project administration, L.K. All authors have read and agreed to the published version of the manuscript.

Funding: This research was funded by National Natural Science Foundation of China, grant number 41877281. Institutional Review Board Statement: Not applicable.

Informed Consent Statement: Not applicable.

Data Availability Statement: The data presented in this study are available on request from the corresponding author.

Conflicts of Interest: The authors declare no conflict of interest.

\section{References}

1. Alshibli, K.A.; Sture, S. Shear band formation in plane strain experiments of sand. J. Geotech. Geoenviron. Eng. 2000, 126, 495-503. [CrossRef]

2. Torabi, A.; Braathen, A.; Cuisiat, F.; Fossen, H. Shear zones in porous sand: Insights from ring-shear experiments and naturally deformed sandstones. Tectonophysics 2007, 437, 37-50. [CrossRef] 
3. Sadrekarimi, A.; Olson, S.M. Shear Band Formation Observed in Ring Shear Tests on Sandy Soils. J. Geotech. Geoenviron. Eng. 2010, 136, 366-375. [CrossRef]

4. Wang, P.; Sang, Y.; Shao, L.; Guo, X. Measurement of the deformation of sand in a plane strain compression experiment using incremental digital image correlation. Acta Geotech. 2019, 14, 547-557. [CrossRef]

5. Chai, J.C.; Jia, R.; Nie, J.X.; Aiga, K.; Negami, T.; Hino, T. 1D deformation induced permeability and microstructural anisotropy of Ariake clays. Geomech. Eng. 2015, 8, 81-95. [CrossRef]

6. Leroueil, S.; Kabbaj, M.; Tavenas, F.; Bouchard, R. Stress-strain strain rate relation for the compressibility of sensitive natural clays. Geotechnique 1985, 35, 159-180. [CrossRef]

7. Burland, J.B.; Rampello, S.; Georgiannou, V.N.; Calabresi, G. A laboratory study of the strength of four stiff clays. Geotechnique 1996, 46, 491-514. [CrossRef]

8. Zhi, Y.; Kong, L.; Guo, A.; Tan, L. Occurrence and engineering properties of structural soft clay in Zhanjiang area. Rock Soil Mech. 2004, 25, 1879-1884.

9. Wang, D.X.; Korkiala-Tanttu, L. On the normalized behavior of naturally and artificially structured clays. Eng. Geol. 2016, 214, 20-28. [CrossRef]

10. Zhou, H.B.; Cai, L.B.; Gao, W.J. Statistical analysis of the accidents of foundation pit of the urban mass rail transit station Hydrogeol. Eng. Geol. 2009, 36, 67-71.

11. Wei, L.T.; Qiang, X.; Wang, S.Y.; Wang, C.L.; Xu, J. The morphology evolution of the shear band in slope: Insights from physical modelling using transparent soil. Bull. Eng. Geol. Environ. 2020, 79, 1849-1860. [CrossRef]

12. Elkamhawy, E.; Wang, H.; Zhou, B.; Yang, Z. Failure mechanism of a slope with a thin soft band triggered by intensive rainfall. Environ. Earth Sci. 2018, 77, 340. [CrossRef]

13. Zhang, G.; Hu, Y.; Wang, L.P. Behaviour and mechanism of failure process of soil slopes. Environ. Earth Sci. 2015, 73, 1701-1713. [CrossRef]

14. Saada, A.S.; Bianchini, G.F.; Liang, L.Q. Cracks, bifurcation and shear bands propagation in saturated clays. Geotechnique 1994, 44, 35-64. [CrossRef]

15. Gylland, A.; Jostad, H.; Nordal, S. Experimental study of strain localization in sensitive clays. Acta Geotech. 2014, 9, 227-240. [CrossRef]

16. Zhang, W.C.; Wang, D. Stability analysis of cut slope with shear band propagation along a weak layer. Comput. Geotech. 2020, 125, 103676. [CrossRef]

17. Thomas, T.Y. Plastic flow and fracture in solids. J. Math. Mech. 1958, 7, 291-322. [CrossRef]

18. Li, B.; Zhao, X.; Dong, J. Experimental study on shear band inclination in Shanghai clay. Rock Soil Mech. 2002, $23,423-427$.

19. Yuan, J.; Zhang, Q.; Li, B.; Zhao, X. Experimental analysis of shear band formation in plane strain tests on Shanghai silty clay. Bull. Eng. Geol. Environ. 2013, 72, 107-114. [CrossRef]

20. Feng, Z.K.; Xu, W.J.; Meng, Q.S. Mechanical behaviors of interaction between coral sand and structure surface. J. Cent. South Univ. 2020, 27, 3436-3449. [CrossRef]

21. Gylland, A.S.; Rueslatten, H.; Paniagua, P.; Nordal, S. Microscopy Techniques for Viewing the Inner Structure of Shear Bands in Sensitive Clays. Geotech. Test. J. 2016, 39, 688-694. [CrossRef]

22. Li, C.; Shu, R. Accurate and simple digital volume correlation using pre-interpolation. Meas. Sci. Technol. 2020, $31,095201$. [CrossRef]

23. Li, C.S.; Kong, L.W.; Shu, R.J.; An, R.; Jia, H.B. Dynamic three-dimensional imaging and digital volume correlation analysis to quantify shear bands in grus. Mech. Mater. 2020, 151, 10364. [CrossRef]

24. Alikarami, R.; Ando, E.; Gkiousas-Kapnisis, M.; Torabi, A.; Viggiani, G. Strain localisation and grain breakage in sand under shearing at high mean stress: Insights from in situ X-ray tomography. Acta Geotech. 2015, 10, 15-30. [CrossRef]

25. Cheng, Z.; Wang, J.F. Experimental investigation of inter-particle contact evolution of sheared granular materials using X-ray micro-tomography. Soils Found. 2018, 58, 1492-1510. [CrossRef]

26. Thakur, V.; Nordal, S.; Viggiani, G.; Charrier, P. Shear bands in undrained plane strain compression of Norwegian quick clays Can. Geotech. J. 2018, 55, 45-56. [CrossRef]

27. Rudnicki, J.W.; Rice, J.R. Conditions for localization of deformation in pressure-sensitive dilatant materials. J. Mech. Phys. Solids 1975, 23, 371-394. [CrossRef]

28. Wanatowski, D.; Chu, J.; Loke, W.L. Drained instability of sand in plane strain. Can. Geotech. J. 2010, 47, 400-412. [CrossRef]

29. Chu, J.; Wanatowski, D. Instability conditions of loose sand in plane strain. J. Geotech. Geoenviron. Eng. 2008, 134, 136-142. [CrossRef]

30. Hong, Z.S.; Zeng, L.L.; Cui, Y.J.; Cai, Y.Q.; Lin, C. Compression behaviour of natural and reconstituted clays. Geotechnique 2012, 62, 291-301. [CrossRef]

31. Rosenqvist, I.T. Considerations on the Sensitivity of Norwegian Quick-Clays. Geotechnique 1953, 3, 195-200. [CrossRef]

32. Zhang, X.W.; Kong, L.W.; Cui, X.L.; Yin, S. Occurrence characteristics of free iron oxides in soil microstructure: Evidence from XRD, SEM and EDS. Bull. Eng. Geol. Environ. 2016, 75, 1493-1503. [CrossRef]

33. Kong, L.W.; Zang, M.; Guo, A.G.; Tuo, Y.F. Effect of stress path on strength properties of Zhanjiang strong structured clay. Rock Soil Mech. 2015, 36, 19-24.

34. Roscoe, K.H. The Influence of Strains in Soil Mechanics. Geotechnique 1970, 20, 129-170. [CrossRef] 
35. Arthur, J.R.F.; Dunstan, T.; Alani, Q.; Assadi, A. Plastic-deformation and failure in granular media. Geotechnique 1977, 27, 53-74. [CrossRef]

36. Hicher, P.Y.; Wahyudi, H.; Tessier, D. Microstructural analysis of strain localization in clay. Comput. Geotech. 1994, 16, 205-222. [CrossRef]

37. Jiang, M.; Peng, L.; Zhu, H.; Lin, Y.; Huang, L. Microscopic investigation on shear band of marine clay in Zhuhai, China. Rock Soil Mech. 2010, 31, 102-108.

38. Zhang, X.; Kong, L.; Guo, A.; Tuo, Y. Experiment study of pore distribution of strong structural clay under different consolidation pressures. Rock Soil Mech. 2014, 35, 2794-2800. 